\title{
Educação Física na Educação Infantil: uma realidade almejada
}

\section{Physical Education in Infantile Education: a longed-for reality}

\author{
Adriana Gentilin Cavalaro* \\ Verônica Regina Muller**
}

\begin{abstract}
RESUMO
O objetivo deste estudo foi verificar a possibilidade de inserção do professor(a) de educação física na educação infantil. Para isso, realizou-se uma pesquisa qualitativa bibliográfica e documental. A partir das categorias: movimento, afetividade e interação ressaltamos a importância deste profissional no processo de aprendizagem e desenvolvimento infantil. Buscou-se, ainda, compreender sua relevância para a primeira infância bem como o papel desta disciplina traduzida em cultura corporal neste âmbito escolar.

Palavras-chave: Educação física; Pedagogia; Educação infantil.
\end{abstract}

\begin{abstract}
The objective of this study was to verify the possibility of inserting the teacher of physical education in the infantile education. For that, took place a bibliographical and documental qualitative research. Starting from the categories: movement, affectivity and interaction, we emphasized that professional's importance in the learning process and infantile development. We also searched out to understand his/her relevance for the first childhood as well as the role of this discipline translated in corporal culture in this school extent.

Keywords: Physical education; Pedagogy; Infantile education.

* Professora de Educação Física e Especialista em Atividade Física e Saúde. E-mail: adriana_cavalaro@hotmail.com

** Professora Doutora da Universidade Estadual de Maringá. E-mail: vm@wnet.com.br
\end{abstract}




\section{Introdução}

A ideia de infância como um período peculiar de nossas vidas não é um sentimento natural ou inerente à condição humana. A partir do Século XVI, com a mudança no modo de produção no Século XVII, a criança passou a ser entendida como fator importante para a aquisição e manutenção dos bens familiares, ou, se não fosse de família de posses, deveria ser educada para o trabalho. Neste sentido, surgiu junto um outro sentimento para com a infância: a moralização. A criança da modernidade passa a ser vista como um ser imperfeito e incompleto, necessitando ser moralizada através da educação feita pelo adulto (KRAMER, 1995).

A criação de escolas para a educação infantil começou no século XVIII, com a Revolução Industrial. A inserção da mulher no mercado de trabalho fez surgir os primeiros estabelecimentos de Educação Infantil no país, no final do século XIX. Eles eram filantrópicos até a década de 1920, quando se iniciou um movimento pela democratização do ensino. Aos poucos o poder público começou a assumir a responsabilidade pela escola dos pequenos. As creches populares atendiam somente o que se referia à alimentação, higiene e segurança física.

Na história recente do Brasil, com a promulgação da Lei de Diretrizes e Bases da Educação Nacional (LDBN) em 1996, a educação até seis anos ficou definida como primeira etapa da Educação Básica. Essa divisão só foi alterada em maio de 2005, com a sansão presidencial à lei Federal $n .^{\circ} 11.114$, que define que crianças com seis anos completos devem ser matriculadas no primeiro ano do Ensino Fundamental. Dessa forma, a educação infantil passou a atender crianças até cinco anos de idade. No mundo contemporâneo, com as novas configurações da família e do trabalho, a frequência dos pequenos à educação infantil tornou-se uma necessidade do grupo familiar e da criança. Se, por um lado, esta etapa de ensino não pode ser entendida como a solução para os problemas da primeira infância, por outro, não é possível desprezar os importantes papéis que ocupa na vida da criança: social, educacional e cultural (CORSINO, 2003).

Sem dúvida, a educação infantil foi uma conquista muito importante para crianças de zero a seis anos e nesse contexto foi necessária a criação de leis específicas da infância e do ensino para regulamentar e organizar essa etapa educacional. 


\section{Aspectos legais da Educação Infantil}

Criado em 1998, o Referencial Curricular Nacional para Educação Infantil (RCNEI) foi desenvolvido para servir de guia de reflexão sobre conteúdos, objetivos e orientações didáticas escolares. Este documento visa a melhoria da qualidade, do cuidado e educação para as crianças de 0 a 6 anos de idade e ainda contribuir para o aperfeiçoamento e qualificação de seus educadores. Dentre os objetivos gerais que o Referencial Curricular Nacional para Educação Infantil estabelece, não há uma referência explícita à educação física, mas sim, que dizem respeito ao "corpo" e ao "movimento", tais como:

- Descobrir e conhecer progressivamente seu próprio corpo, suas potencialidades e seus limites, desenvolvendo e valorizando hábitos de cuidado com a própria saúde e bem-estar;

- Brincar, expressando emoções, sentimento, pensamentos, desejos e necessidades;

- Utilizar as diferentes linguagens (corporal, musical, plástica, oral e escrita) ajustadas às deferentes intenções e situações de comunicação, de forma a compreender e ser compreendido, expressar suas idéias, sentimentos, necessidades e desejos e avançar no seu processo de construção de significados enriquecendo cada vez mais sua capacidade expressiva (VOLUME 1, p. 63).

Já o Estatuto da Criança e do Adolescente (ECA), regulamentado no Artigo 277 da constituição de 1988 e na Lei no . 8.069, de 13 de julho de 1990, "[...] traz em si uma concepção da criança cidadã, o que significa entender que todas são sujeitos de direitos, merecem proteção integral, porque se encontram em condições especiais de desenvolvimento" (MULLER, 2002, p. 6). A mesma autora (2005) pergunta: Qual a relação do professor de Educação Física com o Estatuto da Criança e do Adolescente? E depois esclarece:

Para relacionarmos os artigos diretamente à área, além do artigo 4 do Estatuto que é a reprodução escrita do já citado artigo 227 da constituição federal, em especial, ressaltamos que a Educação Física está citada no capítulo II, do Direito à liberdade, ao Respeito e à Dignidade:

Art. 16. O Direito à liberdade compreende os seguintes aspectos:

IV - brincar, praticar esportes e divertir-se; 
[...] Quanto à responsabilidade do professor como pessoa, podemos trazer o artigo 18 que preconiza como "dever de todos velar pela dignidade da criança e do adolescente, pondo-os a salvo de qualquer tratamento desumano, violento, aterrorizante, vexatório ou constrangedor" (MULLER, 2005, p. 18).

Ainda dentro desse aspecto, temos a Lei de Diretrizes e Bases da Educação Nacional (LDB) que tem por objetivo possibilitar aos sistemas de ensino a aplicação dos princípios educacionais constantes na Constituição Federal. A LDB é, portanto, uma Lei que rege os sistemas de ensino. No Capítulo 2 deste documento está presente o parágrafo $3 .^{\circ}$ onde encontramos: "A educação física, integrada à proposta pedagógica da escola, é componente obrigatório na Educação Básica, [...]" (BRASIL, 1996). Como podemos observar, a educação física está legalmente inserida na educação infantil, pois esta é a primeira etapa da Educação Básica.

Assim, observa-se que a Educação Infantil não só pode, como deve, unir-se às diversas áreas de conhecimento em seu plano pedagógico, para que a criança possa realmente ser vista como um ser indivisível e para que haja a interação que contribua com sua formação integral. A Educação Física é reconhecidamente uma dessas áreas em que urge unir-se à educação infantil, principalmente quando os currículos dos cursos de Pedagogia não oferecem tal disciplina para os(as) profissionais que egressam este curso.

\section{Formação profissional}

O Currículo e Plano Pedagógico dos cursos de Pedagogia e Educação Física da Universidade Estadual de Maringá apresentam objetivos e conhecimentos distintos para a formação dos profissionais que ingressam nesta instituição e que atuarão na educação básica.

Os dois cursos têm o intuito de formar professores aptos ao que se destina cada licenciatura. Contudo, os objetivos do curso de educação física vão um pouco além, pois nos tópicos: "Possibilitar a aplicação de conhecimento nas diversas áreas relativas à educação física;", e "Oportunizar uma maior integração curricular entre as disciplinas oferecidas pelos departamentos de diferentes centros;" nota-se que este curso quer ampliar seus conhecimentos e busca integrarse às demais áreas, articulando, assim, saberes e práticas que não devem ficar reduzidos a uma única disciplina ou a uma única área de conhecimento. 
Na verificação ainda de tais documentos, constata-se que os futuros profissionais de pedagogia não têm disciplinas que contemplem a educação física na sua grade curricular.

Nessa formação não consta um estudo específico sobre Linguagem Corporal ou Cultura de Movimento ou ainda Ludicidade, conteúdos que necessitam como base o "Movimento", o mesmo explícito no Referencial Curricular Nacional para a Educação Infantil e cujo conteúdo não é tratado no curso de Pedagogia da Universidade Estadual de Maringá (UEM) (material original se encontra disponível para consulta). Quanto à educação física, esta estuda o "movimento" nos seus aspectos: fisiológico, psicológico, cultural, social, biológico, educacional, desenvolvimentista, dentre outros.

Como entender então, que um fator tão importante para a formação e desenvolvimento da criança seja trabalhado de forma generalizada?

A intenção aqui não é comparar quantitativa e sequer qualitativamente os dois cursos em questão. O que se pretende é simplesmente investigar se o conhecimento do pedagogo(a), formado(a) para atuar na educação infantil, a cerca do "movimento", quesito esse colocado em destaque no Referencial Curricular Nacional para a educação infantil, é equivalente ao do professor de educação física.

Uma das únicas disciplinas que trabalham o conhecimento sobre "movimento" é a Psicologia da Educação I que vê esse saber através da abordagem Psicomotricista. Faz-se necessário, então, compreender um pouco melhor os sentidos e significados que esta área/disciplina vem empreendendo na escola e também na Educação Infantil. Sayão (1999, p. 49) ressalta que:

Na década de 70, a psicomotricidade surgiu no Brasil como uma possibilidade de "renovar" a concepção esportivizante da Educação Física escolar [...]. Fortemente arraigada à psicologia do desenvolvimento, a psicomotricidade, construiu suas teorias tendo como base os aspectos evolutivos (cognitivos, afetivos, emocionais, psicomotores, sociais, etc.) da infância e da adolescência com o objetivo de observar e constatar as mudanças no comportamento dos indivíduos ao longo de sua existência $[\ldots]$.

E assim,

[...] as habilidades psicomotoras - conhecimento do esquema corporal, 
lateralidade, percepção espaço-temporal, equilíbrio... tornaram-se conteúdos da Educação Física ou do “domínio psicomotor” na Educação Infantil [...] criando uma subárea que agregaria Psicologia à Motricidade, ou melhor, "domínio cognitivo e domínio psicomotor” (SAYÃO, 1999, p. 50).

Dessa forma, a Educação Física confundida em alguns casos com a Psicomotricidade, passa a ser uma auxiliar das demais áreas que compõem o currículo escolar onde sua função é preparar ou colaborar com aprendizagens de cunho cognitivo, esquecendo-se de que esta possui conhecimentos próprios. Não se descarta os saberes produzidos por esse campo do conhecimento, o que se questiona é seu papel na educação infantil (SAY ̃̃O, 1999).

\section{Educação Física na Educação Infantil}

Refletir sobre educação física na educação infantil é desafiador, sobretudo quando pensamos em possíveis tensões existentes na presença do profissional de educação física inserido no ensino de zero a seis anos. Estamos falando da relação entre professor especialista atuando junto com o unidocente (pedagogo). A grande preocupação em torno desse assunto é de assumirmos já na educação infantil um modelo "escolarizante", organizado em disciplinas e com uma abordagem fragmentária de conhecimento (AYOUB, 2005). Os estudos de Sayão (2002, p. 59) esclarecem que:

Numa perspectiva de Educação Infantil que considera a criança como sujeito social que possui múltiplas dimensões, as quais precisam ser evidenciadas nos espaços educativos voltados para a infância, as atividades ou os objetos de trabalho não deveriam ser compartimentados em funções e/ou especializações profissionais. Entretanto, a questão não está no fato de vários profissionais atuarem no currículo da Educação Infantil. O problema está nas concepções de trabalho pedagógico desses profissionais que, geralmente fragmentam as funções de uns e de outros se isolando em seus próprios campos. '[...] Portanto, não se trata de atribuir 'funções específicas' para um ou outro profissional e designar 'hora para a brincadeira', 'hora para a interação' e 'hora para linguagens"”. O professor de Educação Física deve ser mais um adulto com quem as crianças estabelecem interações na escola. No entanto, só se justifica a necessidade de um profissional dessa 
área na Educação Infantil se as propostas educativas que dizem respeito ao corpo e ao movimento estiverem plenamente integradas ao projeto da instituição, de forma que o trabalho dos adultos envolvidos se complete e se amplie visando possibilitar cada vez mais experiências inovadoras que desafiem as crianças.

E a autora complementa:

Diferentes profissionais podem atuar num mesmo currículo com as crianças pequenas, desde que assumam a idéia de formação solidária. Ou seja, uns e outros compartilham experiências que têm como fim a qualidade do trabalho desenvolvido. A troca constante dos saberes deve prevalecer sobre as atitudes corporativas que colocam a disputa pelo campo de trabalho acima das necessidades e interesses das crianças (SAY ÃO, 2002, p. 60).

Na realização desta pesquisa, não houve conhecimento da existência de projetos na cidade de Maringá (Paraná, Br), em que professores especialistas e unidocentes, no caso, professores de educação física e pedagogos, desenvolvam trabalho em conjunto. Entretanto, podemos citar dois exemplos onde isso já acontece, e o resultado é considerado bastante positivo. O primeiro, acontece na cidade de Campinas - SP, onde a Rede Municipal de Ensino não possui especialista em educação física na esfera da educação infantil. Sob a coordenação da Professora Doutora Eliana Ayoub, da Faculdade de Educação - Unicamp - os alunos estagiários traçam propostas de trabalho inspiradas, sobretudo, na abordagem Crítico-Superadora da educação física, aplicam estas propostas na Rede Municipal de Ensino e posteriormente registram nos relatórios de estágio, da Prática de Ensino de Educação Física e Estágio Supervisionado, as experiências desta área, na educação infantil.

Vem de Santa Catarina o segundo exemplo onde este trabalho em conjunto pode dar certo. A temática educação física na educação infantil toma como ponto de análise e experiência um trabalho que vem se desenvolvendo na Rede Municipal de Ensino de Florianópolis - SC (RME), na qual desde 1982 encontramos professores de educação física atuando em creches e Núcleos de Educação Infantil que atendem crianças, geralmente na faixa de quatro a seis anos de idade em meio período. Essa experiência da RME tem levado alguns pesquisadores ao aprofundamento dos estudos acerca da infância e da educação física no currículo das instituições voltadas para as crianças pequenas. 
Trata-se, portando, de compreender melhor esse fenômeno ainda bastante desconhecido e que carece substancialmente de investigação.

É, então, a partir dessa política da Rede Municipal de Ensino que esses estudiosos repensam o currículo de formação de professores do curso de Educação Física da Universidade Federal de Santa Catarina, pois muitos profissionais, já graduados ou não, se deparam com a possibilidade de atuarem pedagogicamente com crianças pequenas. Esta experiência está circunscrita ao Núcleo de Desenvolvimento Infantil (NDI) da Universidade Federal de Santa Catarina, aos cuidados do coordenador do Núcleo de Estudos e Pesquisas Educação e Sociedade Contemporânea Professor Doutor Alexandre Fernandez Vaz (SAYÃO, 2002).

Então, como será possível articular diferentes profissionais em uma proposta pedagógica que amplie esse contexto?

A resposta pode vir do exemplo sugerido pelo grupo de estudos que, como citado anteriormente, é realizado pela UFSC em conjunto com a Rede Municipal de Ensino de Florianópolis:

Tanto o planejamento das atividades quanto sua ministração foram elaborados conjuntamente pelo professor (especialista) e pelas Professoras (unidocentes). Elas, as Professoras elencavam temas que poderiam ser trabalhados pelo professor de Educação Física e participavam ativamente de todos os momentos. Aquela prática, por nós conhecida, que "entrega" as crianças para o professor/a de Educação Física e as retorna ao final do tempo estabelecido para a aula não acontecia. O tempo de uma atividade poderia ser de 15 minutos ou até de uma manhã ou tarde inteira, conforme os/as profissionais fossem sentindo a necessidade de as crianças permanecerem envolvidas no trabalho. Observamos um momento de construção de alguns brinquedos pelas crianças, no qual o envolvimento de todas se estendeu por, aproximadamente, três horas (SAYÃO, 2002, p. 52).

A possibilidade da formação permanente desses profissionais, a troca constante de experiências e o relato das práticas favorecem um clima de companheirismo e solidariedade entre os professores e os outros profissionais que atuam nas instituições infantis, viabilizando a reflexão constante da docência (SAYÃO, 2002). 


\section{Conclusão}

Dado o exposto, torna-se cada vez mais evidente e necessária a articulação entre educação física e educação infantil. As bases teóricas utilizadas acerca do conceito de infância mostraram-nos que esta fase da vida necessita hoje ser compreendida como categoria social e cultural, pois a criança é criadora de cultura, é capaz de transformar-se e transformar o que a cerca. Os exemplos citados na fase final da pesquisa deixam claro que é possível o trabalho entre o professor de educação física e de outras áreas. Entretanto, sabemos que existem alguns empecilhos que tornam o processo um pouco mais demorado do que gostaríamos.

Sabemos das dificuldades financeiras por que passam as prefeituras municipais, que contam, muitas vezes, somente com o que arrecadam para arcar com os custos com a educação e com cursos para atualização de professores. Mas, para termos educação de qualidade, o investimento financeiro, quer seja Estadual ou Federal, é fundamental.

A falta de conhecimento sobre o tema é outro problema que enfrentamos. Grupos de estudo, pesquisas, palestras, seminários, são algumas respostas que podemos apresentar para tentar amenizá-lo. Os exemplos das Universidades Federal de Santa Catarina e de Campinas - SP mostram que o berço para novas pesquisas são as Academias e que estas são levadas às escolas em forma de projetos, pelos acadêmicos, transformando pequenas ideias em pensamentos que podem mudar o processo pedagógico escolar no futuro.

Somente podemos defender o que conhecemos bem. O tema "movimento" faz parte da área de estudos da educação física e sabemos da sua importância, em todos os aspectos, para o ser em desenvolvimento. Todavia, torna-se necessário que se tenha conhecimento sobre o assunto para lutar em prol de que este professor (de educação física) atue nesta área e seja valorizado.

Assim, defendemos que, sobretudo com a criança, a temática do "movimento" ou da educação física seja trabalhada de forma integrada entre o professor de educação física e o professor da sala de aula (pedagogo).

Nossos apontamentos não se esgotam aqui, é preciso retomá-los e articulálos às práticas daqueles(as) que atuam com as crianças pequenas nas instituições de educação infantil com a crescente produção de pesquisa. Há ainda várias questões para serem aprofundadas que favorecerão um avanço na produção na área educacional. 


\section{REFERÊNCIAS}

ÁRIÈS, P. História Social da Infância e da Família. Tradução de: D. Flaksman. Rio de Janeiro: Guanabara, 1981.

AYOUB, E. Narrando Experiências com a Educação Física na Educação Infantil, Revista Brasileira de Ciências do Esporte, Campinas, v. 6, n. 3, p. 143-158, maio 2005.

BRASIL. Ministério da Educação e do Desporto, Secretaria de Educação Fundamental, Coordenação Geral de Educação Infantil, Referencial Curricular Nacional para Educação Infantil, Conhecimento de Mundo, v. 3, Brasília-DF, 1998.

CORSINO, P. Infância, Linguagem e Letramento: Educação Infantil na Rede Municipal de Ensino do Rio de Janeiro. Tese (Doutorado) - Departamento de Educação, PUC, Rio de Janeiro, 2003.

KRAMER, S. A Política do Pré-Escolar no Brasil: A Arte do Disfarce. 5. ed. São Paulo: Cortez, 1995.

MULLER, V. R. et al. Crianças e Adolescentes: a arte de sobreviver. Maringá: Eduem, 2002.

MULLER, V. R.; MARTINELI, T. A. P.. O Estatuto da Criança e do Adolescente: um Instrumento Legal do Professor de Educação Física, Revista Brasileira de Ciências do Esporte, Campinas, v. 26, n. 3, p. 9-24, maio 2005.

SAYÃO, D. T. Corpo e Movimento: Notas para problematizar algumas questões relacionadas à Educação Infantil e à Educação Física, Revista Brasileira de Ciências do Esporte, Campinas, Colégio Brasileiro de Ciências do Esporte, v. 23, n. 2, p. 5567, jan. 2002.

- A Disciplinarização do Corpo na Infância: Educação Física, Psicomotricidade e o Trabalho Pedagógico. In: SAYÃO, D. T.; MOTA, M. R. A.; MIRANDA, O. (Org.). Educação Infantil em Debate: idéias, invenções e achados. Rio Grande: Fundação Universidade Federal do Rio Grande, 1999.

- Infância, Prática de ensino de Educação Física e Educação Infantil. Educação do Corpo e Formação de Professores: Reflexões Sobre a Prática de Ensino de Educação Física. Florianópolis: Ed. da UFSC, 2002. 